
Not for reproduction, distribution or commercial use.

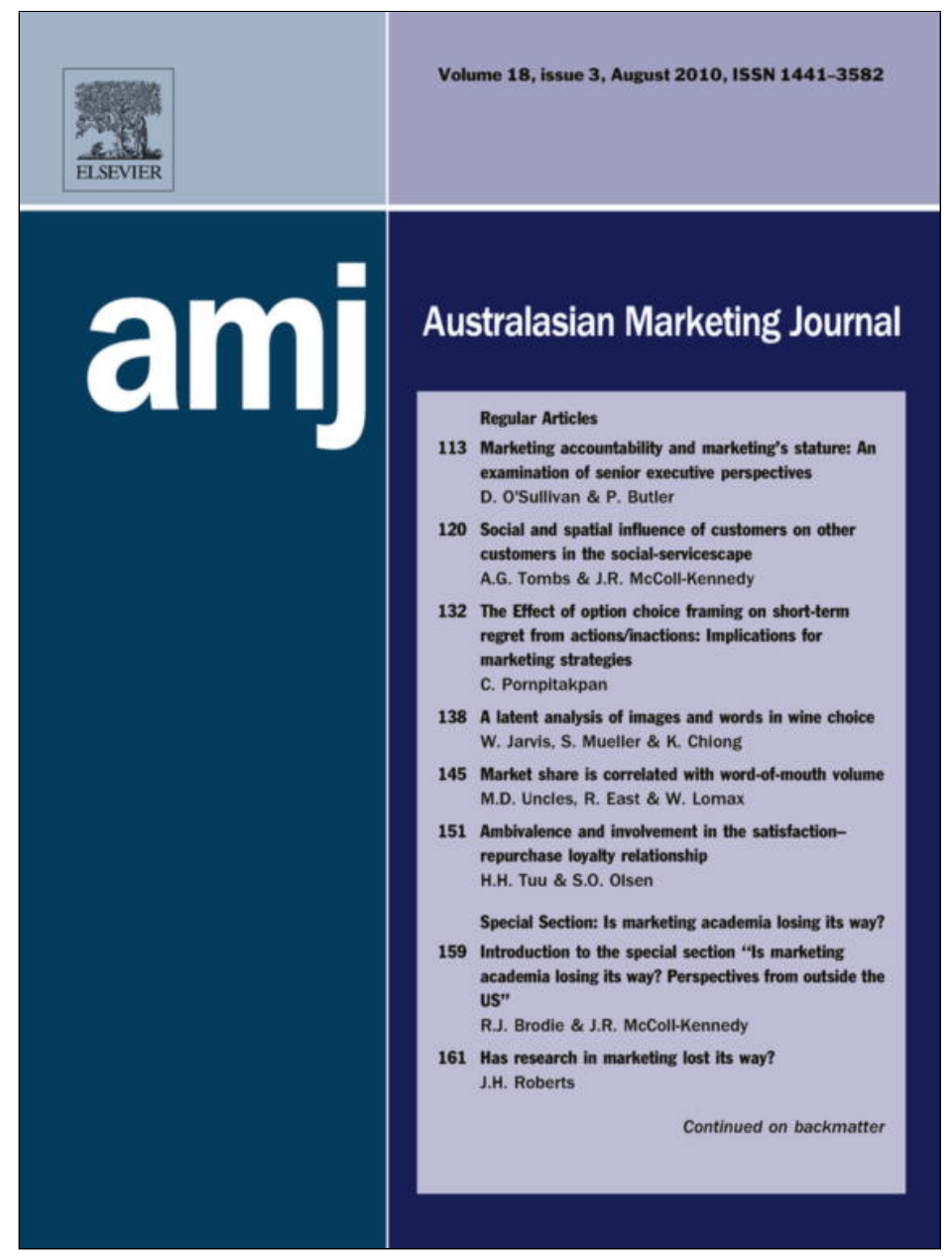

This article appeared in a journal published by Elsevier. The attached copy is furnished to the author for internal non-commercial research and education use, including for instruction at the authors institution and sharing with colleagues.

Other uses, including reproduction and distribution, or selling or licensing copies, or posting to personal, institutional or third party websites are prohibited.

In most cases authors are permitted to post their version of the article (e.g. in Word or Tex form) to their personal website or institutional repository. Authors requiring further information regarding Elsevier's archiving and manuscript policies are encouraged to visit:

http://www.elsevier.com/copyright 


\title{
Has research in marketing lost its way?
}

\author{
John H. Roberts \\ Australian National University, Australia \\ London Business School, United Kingdom
}

\begin{abstract}
A B S T R A C T
Academic research in marketing has made significant strides in improving the methods by which it seeks to understand consumers' behaviour and their response to management actions. Yet, at the same time there is some evidence that these advances may be occurring at a cost of accessibility of its approaches and findings to practising managers. This paper considers how research in marketing might be focused to better meet to needs of practitioners without losing the benefits that come from a rigorous and careful grounding. (ㄷ) 2010 Australian and New Zealand Marketing Academy. Published by Elsevier Ltd. All rights reserved.
\end{abstract}

\section{Introduction}

Recent research has suggested that research in marketing is becoming peripheral to the tasks that managers undertake in the marketplace (e.g., Reibstein et al., 2009). However, other research argues that marketing has a need to more firmly establish its axiomatic roots and should not be a servant to atheoretical, empirical data mining. See, for example, the PhD training course in theory rich marketing, conducted at Duke University in $2007 .{ }^{1}$ This paper discusses whether the research agenda in marketing has lost its way by firstly considering what the "right" way of marketing might be, and before turning to the traditional question of possible trade offs between rigour and relevance in the profession. The paper proposes how to maximize both effectiveness and efficiency with respect to the efficient frontier of relevance and rigour, and offers some prescriptions as to how to improve the position of the profession with respect to these two important criteria.

\section{What is the right way for marketing?}

While there are many dimensions along which to define the "right" way for marketing, in this paper I would like to focus on rigour (undertaking research in a way that is built on strong theory, minimizes threats to reliability and validity, and has a strong thread of logic that links its various elements (e.g., Varadarajan, 2003)) and relevance (undertaking research in a way that is easily applied by managers to provide insight and guidance along the dimensions of possible marketing action. See, for example, Little, 1979). ${ }^{2}$

\footnotetext{
E-mail addresses: john.roberts@anu.edu.au, jhroberts@london.edu

1 http://faculty.fuqua.duke.edu/trm/ Accessed December 19, 2009.

2 In this paper, discussion is almost exclusively in terms of quantitative approaches to research in marketing. That is not to diminish the importance of behavioural research which I believe faces similar if not greater problems.
}

Before one discusses trade offs between rigour and relevance, one should first discuss whether one must make such a trade off. In a sense, understanding what it takes to conduct "good" research is a special case of the study of competitive advantage. Both address the question of where to excel and with which tools. The two dimensions of "winning" in research (rigour and relevance) may be considered analogues to Porter's (1980) differentiation and low cost ways of gaining competitive advantage. Using this simile, one might advise the researcher (as Porter does in the case of differentiation and low cost) that she should make a discrete decision about her target market and then strategies, choosing rigour for an academic audience or relevance for a managerial one, being careful not to be "stuck in the middle."

However, I question how well this dichotomous analogy to Porter serves us. Are rigour and relevance mutually exclusive? Are they even two opposite poles of the same continuous dimension? I think not. We have all seen sloppy research that has no relevance. The literature also contains research that has a very strong foundation and has had considerable impact in throwing light on real marketing applications (e.g., see Roberts et al., 2008). However, neither can we argue that the two attributes are the same end of one dimension ("good" research). Again, we all know of the tradeoffs that must be made in preparing work for an academic journal and for a consulting client. The objective functions, and thus the criteria, are different.

For that reason it is probably best to represent any piece of research in two dimensional space, depicting both its relevance and its rigour. From a supply perspective, we can represent the relevance and rigour attainable for a specific piece of research, given its resource constraints, by the curve marked " $\mathrm{S}$ " in Fig. 1. We can use this diagram to examine how we might improve the usefulness of any piece of research to an individual, given her trade off between relevance and rigour (the demand curve).

This entails considerations of both efficiency (driving the supply curve out further) and effectiveness (ensuring that one is at the 


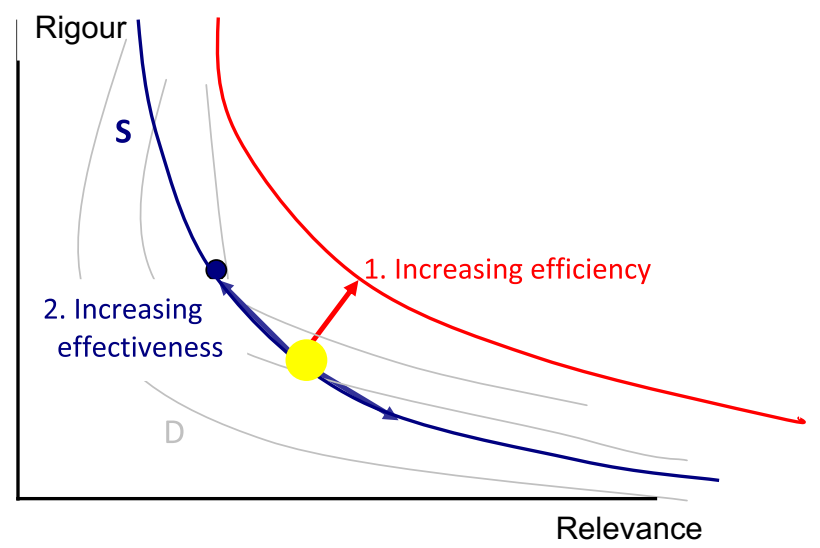

Fig. 1. Maximising the value of research in terms of rigour and relevance.

point on the supply curve that maximizes the utility of the target audience).

These strategies are indicated by arrows 1 and 2 respectively in Fig. 1.

\section{Improving efficiency}

The best way to push out the efficiency frontier, represented by the blue supply curve of research in Fig. 1, is to understand the constraints that lead to the need to trade off rigour and relevance. What is it about rigour that leads to a loss of relevance? And what is it about relevance that leads to a loss of rigour? Some answers readily arise to address this question. Managerial applications tend to be much more time critical both in terms of deadlines and in terms of the cost-benefit equation of when it is no longer useful to investigate a problem further. Thus the onus of proof is often lower in managerial applications, partly because learning by trial and error is a valuable tool in the marketplace, but one on which our journals frown. The higher onus of proof in academia (making fewer Type I errors but more Type II ones than a manager would be happy with), ironically limits the learning it can achieve. Another difference between the trade offs of managers and academics is with respect to external validity and robustness. The manager, by and large, is interested in what is immediately relevant to her. The academic is vitally concerned about the limits to that knowledge, and thus the range of relevance must be a great deal higher for the latter, requiring robustness beyond the immediate environment.

Once we understand these constraints we can attempt to loosen them. The first constraint to better trade offs is obviously a lack of information. Immersion of academics into industry and managers into academic fora would obviously lead to a better mutual understanding of the two value sets, a prerequisite to addressing differences between them. Roberts (2000) suggests a number of ways in which to then address those differences by changes in locus, scope and focus, illustrated in Fig. 2.

Beyond communications and the creation of communication vehicles, is the design of tools. Lilien and Rangaswamy's (2004) Marketing Engineering represents a great way of making the tools of marketing science accessible to the manager. Urban and Karash's (1971) evolutionary model building approach gives managers a way to feel comfortable with simple, robust models before basing decisions on more complex, but less accessible ones. The rise of a group of highly sophisticated marketing intermediaries (analysts with excellent marketing science skills and a strong understanding of the dimensions of management action that analysis must inform) has been useful in the diffusion of state of the art knowledge and an understanding of the problems for which managers have no good solutions, thus representing a gap in the market (e.g., see Roberts et al., 2008).

\section{Improving effectiveness}

Improving effectiveness suggests getting to a point in the graph that is more highly valued by the target market. To address that challenge we need to know the preference functions for users of research (the demand function) represented by the grey iso-utility curves in Fig. 1. Given the user values represented in Fig. 1, she would clearly be on a higher (grey) utility curve if the research sacrificed a little relevance at the yellow point and moved to the blue point.

To understand these trade offs we can return to the competitive advantage analogy. Hunt and Morgan, 1995, Fig. 1) suggest that rather than deciding whether to be low cost or high value (differentiation), the manager should decide the degree to which competitive advantage should come from a better cost structure and the degree to which it should come from more value added. In our case, the researcher must decide on the user's marginal rate of substitution of rigour for relevance (demand) and compare that with her marginal rate of substitution in supply. An optimum will be achieved where the two families of graphs (the grey demand ones and the blue/red supply ones) are tangential.

However, using our competitive advantage analogy, we can use a number of mechanisms to improve this trade off. First, it does not have to be one dimensional. The design of research is multi-dimensional so this optimisation can be conducted for every aspect of design in a manner analogous to how value curves have been used in marketing. For example, for EasyJet to take on British Airways, Kumar (2004) suggests that only with respect to new planes and a refund if late should Easyjet seek a point of difference over BA, because that is the only area for which the target market will value the benefits gained more highly than the cost incurred (see Fig. 3).

The second technique that can improve utility is to recognise that for many research projects there are multiple stakeholders and the needs (utility functions) of each group of stakeholders are likely to be different. Again, marketing in practice has some valuable lessons for us here. Just as Gillette attempts to create as much value as possible (and capture the consumer surplus thus created), by launching a series of razors (base, Custom Plus, Sensor, M3, Mach 3, Mach 3 Turbo, etc.), so too can the researcher create a number of products, targeted at a number of different markets, using the same piece of research. While each "product" will incur its own costs, there will also be a number of joint costs that can be amortised across them all. One example of this is the defense work that I undertook for Telstra when Optus entered the Australian telecommunications market. The work appeared in Marketing Science (Roberts et al., 2004, 2005), but was also published by the Harvard Business Review (Roberts, 2005) and numerous other industry outlets.

\section{The current state of the trade off: a personal view}

Given the somewhat theoretical approach that this paper has adopted thus far as to how marketing research can better find its way, the question naturally arises as to how well it is doing in practice. Is this a major problem for us, or something that we pretty much have a handle on? I think that the answer depends on one's perceptive. If one looks at path breaking applications and world's best practice, then the answer is very positive. However, if one moves to most common practice (and market penetration of our tools), I personally find the result particularly depressing, 


\section{Current Practice}

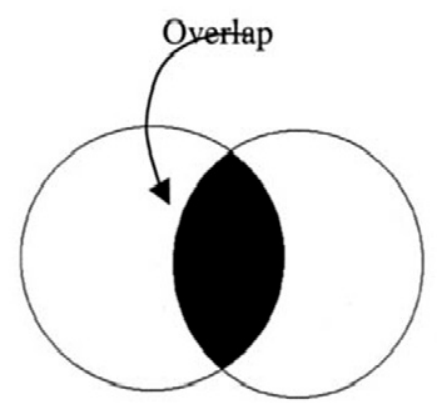

Model capabilities Managerial needs

\section{Market driven ways to increase modelling applications}

a) Change modelling locus

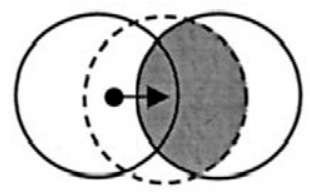

b) Change modelling scope

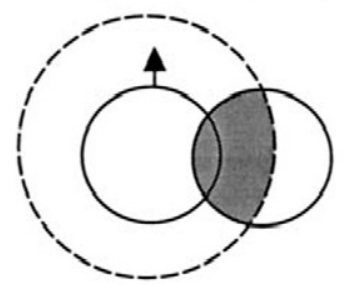

c) Change modelling focus

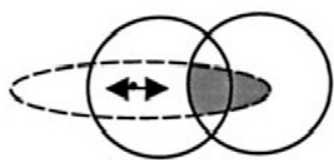

2. Market driving ways to increase modelling applications.

a) Change manager's locus

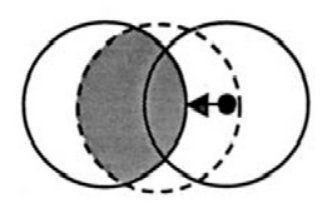

b) Change manager's scope

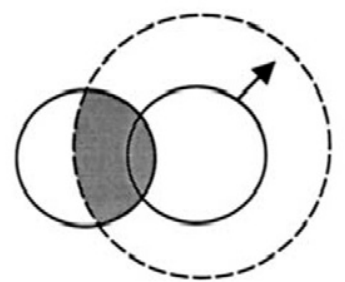

c) Change manager's focus

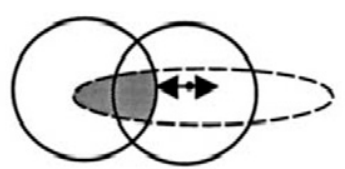

Fig. 2. Means of improving the efficiency of the Rigour versus Relevance tradeoff (Roberts, 2000).

\section{Value Curves of easyJet Versus Flag Carriers}

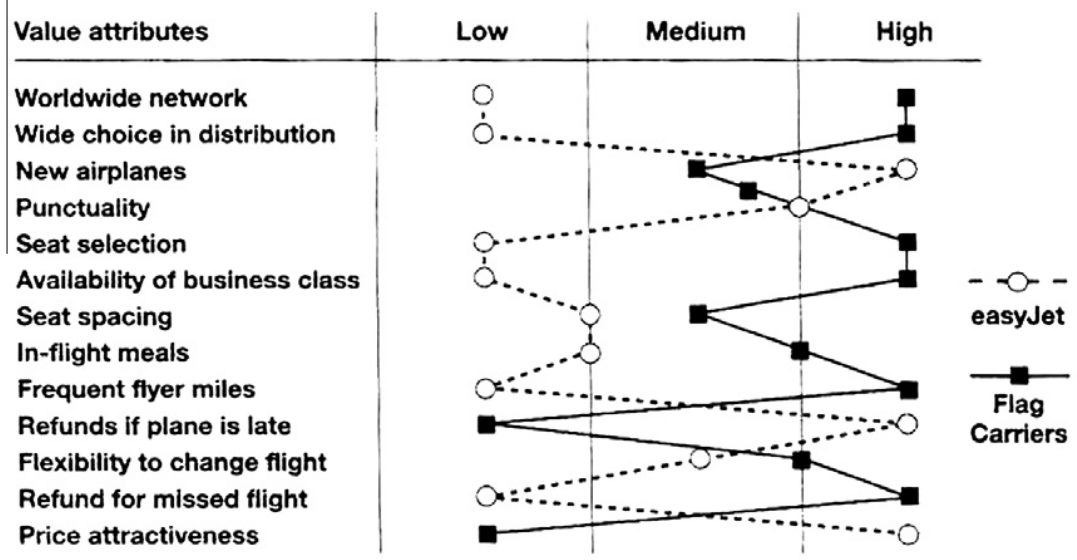

Fig. 3. Maximising effectiveness by designing to where marginal cost equals marginal utility for each design feature. 
especially if we compare ourselves with fields such as finance and accounting.

My own view is that during the 1970s there was a move from an economics approach to a marketing approach in the way many problems were addressed, largely as a result of the operations research methods adopted by Little and his contemporaries (e.g., Little, 1979). From there, more recently we have moved to establish strong paradigms (accepted, rigourous ways in which to address certain classes of problem). Examples include better scaling approaches, discrete choice models, and the incorporation of heterogeneity. While it is hard to argue that this is not a good thing, I believe that there is a real danger that we could drown in our own esoterica. We can go from being vaguely right to precisely wrong; from understanding importance differences to understanding only differences in statistical significance. If this is indeed happening, we would expect to see a rise in competitors, just as marketing offered competition to micro economics forty years ago. We are seeing that. Database marketing is becoming the domain of the IT department, much of the exciting work in social marketing is now conducted in behavioural economics, and service quality and management is an area of great interest in organisational behaviour. This list goes on.

This does not mean that we should retreat to our operations research roots or from our superior statistical techniques. However, think that it does provide strong prima facie evidence that we need to improve our performance on how we cover the demand side of Fig. 1.

\section{Summary and some suggested remedies}

A number of remedies have been proposed throughout this paper. I would like to emphasize some major ones in closing. Many are in progress, but clearly, more work is needed.

- Forums for communication: In the 1983 Marketing Science Conference at USC, half of the forty or so participants were from industry. Today, it would be unusual for more than half a dozen of the five hundred attendees to be from such a background. The Society for Marketing Science is attempting to address this issue by the introduction of a biennial Practice Conference which has achieved some success.

- Tools and access: When I started teaching Marketing Management I would think nothing of getting my students to undertake simple differentiations and maths. Now, I would not dare. Some scholars, such as Bruce Hardie at the London Business School, with his Analytical Marketing subject are fighting back against this trend and, together with tools like Marketing Engineering, this gives us hope.

- Joint projects: The Marketing Science Institute has played a wonderful role in bringing together world class academics and leaders of its member companies (who represent many of the
Fortune 500 companies). It has now instituted a "Bridge Committee" to increase the number of state of the art projects being undertaken, as well as circulating the results to its members through its working paper series. Similarly, the Society for Marketing Science has instituted a prize for best practice which is celebrating the best collaboration between industry and academia.

- Immersion: We need better forms of immersion. Junior professors should be encouraged to stop their clocks and enter industry for a while. Similarly, managers can use universities as an incubator in which to examine problems requiring more head space than is afforded in industry.

- Marketing intermediaries: Marketing analysts working in consulting companies, within major firms and in institutions, have a major role to play in translation. Marketing line managers cannot be expected to understand the potential of marketing researchers to successfully add focus to their activities. Marketing academics, by and large, are a long way from understanding the dimensions of management action. Marketing intermediaries often have a very good understanding of both. Their role in institutions such as the American Marketing Association's Advanced Research Techniques Forum, offers a good way to accelerate the meeting of the manager's problem and the academic's potential solution.

This is not a problem that is going to disappear, but it is one in which we must continue to strive to provide vehicles to assist us to do better.

\section{References}

Hunt, Shelby D., Morgan, Robert, 1995. The comparative advantage theory of competition. Journal of Marketing 59 (2), 1-15.

Kumar, Nirmalya, 2004. Marketing as Strategy. Harvard Business Publishing Service, Soldiers Field.

Lilien, Gary, Rangaswamy, Arvind, 2004. Marketing Engineering: ComputerAssisted Marketing Analysis and Planning Revised Second ed. (Paperback). Trafford Publishing, Bloomington, IN.

Little, John D.C., 1979. Decision support systems for marketing managers. Journal of Marketing 43, 9-26 (summer).

Porter, Michael, 1980. Competitive Strategy. New York, The Free Press.

Reibstein, David, Day, George, Wind, Jerry, 2009. Guest editorial: is marketing academia losing its way? Journal of Marketing 73, 1-3.

Roberts, John, 2000. The intersection of modelling potential and practice. International Journal of Research in Marketing 13 (3), 127-134

Roberts, John, 2005. Defensive Marketing. Harvard Business Review (November)

Roberts, John, Kayande, Ujwal, Stremersch, Stefan, 2008. From Academic Research to Marketing Practice: Exploring the Marketing Science Value Chain Working Paper. London Business School.

Roberts, John, Morrison, Pamela, Nelson, Charlie, 2004. Implementing a prelaunch diffusion model: measurement and management challenges of the Telstra switching study. Marketing Science 23 (2), 186-191.

Roberts, John, Nelson, Charlie, Morrison, Pamela., 2005. A prelaunch diffusion model for evaluating market defense strategies. Marketing Science 24 (1), 150-164.

Urban, Glen, Karash, Richard, 1971. Evolutionary model building. Journal of Marketing Research 8 (1), 62-66.

Varadarajan, P.R., 2003. Musings on relevance and rigor of scholarly research in marketing. Journal of the Academy of Marketing Science 31 (4), 368-376. 